\title{
Development of data model for the functioning of production active elements based on information interaction
}

\author{
I N Khaimovich ${ }^{1,2}$ and V M Ramzaev ${ }^{1}$ \\ ${ }^{1}$ Samara University of Public Administration International Market Institute, \\ G.S. Aksakova Street 21, Samara, Russia, 443030 \\ ${ }^{2}$ Samara National Research University, Moskovskoe shosse 34A, Samara, Russia, 443086
}

\begin{abstract}
The article discusses the design and technological preparation of production as a hierarchical active system "center - designers - technologists". A functioning model of the production of the active element, which is a model of decision making, is described in a formalized form. The most effective state, chosen by each active member as a team of a relative subdivision, may be different from the planned states that are defined in terms of the criterion which characterizes given type of production preparation in general, which leads to contradictions in the system. The article introduces quantitative assessment of inconsistency between each team and the center, and on this basis the coordinated interaction problem is stated. The authors discuss the informative way of solving the coordinated interaction problem from the standpoint of team interests: the availability of information resources in the form of PDM/PLM - the management system of product life cycle with implemented Big Data technology will allow designers and technologists to create adequate representation of actions of another team and reach optimum equilibrium. The mechanism of effective design and engineering solutions formation is connected with the mechanism of versions and organization of information processing level Product Event Management.
\end{abstract}

\section{Introduction}

In modern conditions, a unified information space (UIS) is actively used in the organization of machinery production, which includes all information related to the product and provides information support for all stages of the product life cycle, i.e. the UIS should become the only reliable source of latest data. The foundation of information data of the enterprises is the data obtained in the process of design and technological preproduction. As when making agreed decisions between design and technological services, it is necessary to make multiple changes, the number of design and technological documentation undergoes multiple version creation of documents in the enterprise database $[1,2]$. Particularly relevant the mechanism of version creation becomes in the aerospace industry, since, on average, the aircraft consists of several million products made in different regions of the globe from different materials [3, 4], and the solution for each product is adopted using the version mechanism. To integrate such data volumes, the BIG DATA mechanism is used in product data management systems (PDM systems), for example, in the TEAMCENTER software. 
To work out the version mechanism, it is necessary to place all agreed decisions between designers and technologists in the database. Let us consider necessary and sufficient conditions for ensuring coordinated interaction between the units.

The relevant objective of design and engineering production preparation (DEPP) management is the task of coordination of resource flows between separate shops and sites. The solution of this particular task is connected with defining the control actions which are plan targets for permissible set of resource flows $[5,6]$. However recently to solve the problem of coordination of resource flows it is necessary to achieve balanced interaction between subsystems of DEPP based on the estimation of their activities to fulfill the required administrative objectives. The procedure of coordination in this case is understood as sequential control and achievement of balance between local targets of subsystems of DEPP which are complied with the common (global) goal of the system [7]. So far as it is supposed that active systems have their own goals, then the task description and control mechanisms work out will be made in terms of systems with active elements (AE).

Let us consider the control scheme with the help of design and engineering production preparation and formalize control problem. Hierarchical control system of DEPP, presented in the figure 1 is realized in the form of organization systems (OS), including control subsystem of upper level (center), controlled and simultaneously controlling subsystems of $\mathrm{AE}$ of lower level, as well as external environment. The center is the leader of OS, the active elements are the teams of designers (DAE) and production engineers (technologists) (TAE), and the external environment is the outlet market or Ordering Customer. The subject to control is the product project including the stages and resources of life cycle (LS) from designing to production. The object is product specified by $Y$ which are characterized by a set of global parameters $Q$, a list of target requirements to the product (consumer property of a product), specified in the technical project on a product:

$$
Q=Q\left(q_{i}^{k o n}, q_{j}^{\text {tec }}\right), \quad i=1, \ldots, L ; \mathrm{j}=1, \ldots, \mathrm{M},
$$

where $q_{i}^{k o n}, q_{j}^{\text {tec }}$ are the parameters of LC of a product according to the production design and to the technology process, $L$ is the number of requirements to the design, $M$ is the number of requirement to the technology process. In the present case vector $Q$ depends only on the product design $Y$, i.e. in (1) vector $q^{k o n}$ is included in the explicit form, and vector of technological parameters $q^{\text {tec }}$ - in implicit form. At any specific time $t$ LC of a product $Y$ is in the condition of $\mathrm{Y}(Q(\ldots, t))$. In this regard the global target function of the center is to achieve the condition of

$$
Y_{\text {opt }}^{\text {Nesh }}=Y\left(\mathrm{Q}\left(\mathrm{q}_{i}^{\text {kon }}, \mathrm{q}_{j}^{\text {tec }}, \mathrm{n}, \mathrm{t}\right)\right)
$$

for the time $t \leq t_{\Sigma}$, when the current parameters $\mathrm{Q}\left(\mathrm{q}_{i}^{k o n}, \mathrm{q}_{j}^{\text {tec }}, \mathrm{n}, \mathrm{t}\right) \approx Q$ achieve or exceed target values $Q$. In formula (2) $\mathrm{n}$ is the target figure of the amount (line) of product $Y$. To achieve a global task the center controls the lower level and generates target figures $x=\left\{Q, n, t_{\Sigma}\right\}$, and controlled subsystems of lower systems perform their implementation, developing their own tasks within $\mathrm{AE}$ $K_{x i}$ and $T_{x i}$ - for DAE and TAE correspondingly (figure 1). The management of AE is fulfilled by the groups of people - teams which are able to achieve goals independently, the latest are manmachine systems providing production yield $Y_{t}$. The supervisory activity of the center is carried out by monitoring of qualitative characteristics $Y_{t}$, which are connected with some controlled variables in design and technology of a product in DEPP [8]. If we consider the LC system processes from the point of view the document - centric approach then the output quality in DEPP may be indirectly estimated in terms of volume of project (design and technological) documentation with minimum 
amount of changes. To achieve the necessary level of quality it is required to optimize target functions of TAE and DAE.

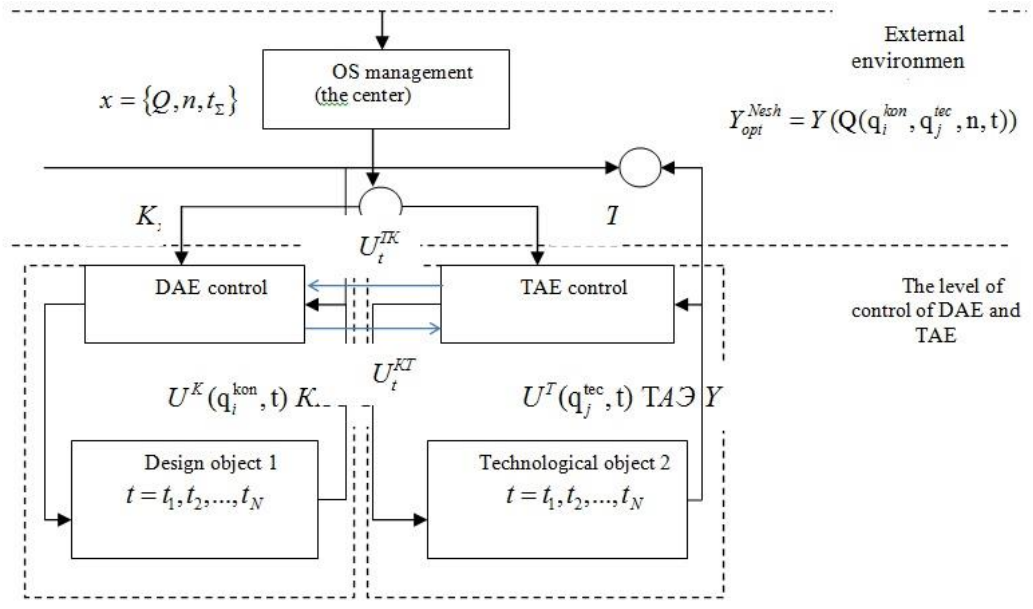

Figure 1. The structure of DEPP management system with independent elements.

Let us present a model for DEPP control system in formalized way, in this case to describe its functioning it is possible to apply the theory of reflexive games or network programming methods $[9,10,11]$ as it will be shown below.

Control in DEPP is represented in the form of multivariable mathematical model:

$$
\left\{\begin{array}{l}
t_{\min }=\underset{t}{\arg \min } Y_{o p t}^{\text {Nesh }} \\
Y_{o p t}^{\text {Nesh }}=Y\left(\mathrm{Q}\left(\mathrm{q}_{i}^{\text {kon }}, \mathrm{q}_{j}^{\text {tec }}, \mathrm{n}, \mathrm{t}\right)\right) \\
\mathrm{q}_{i}^{\text {kon }} \leq\left(\mathrm{q}_{i}^{\text {kon }}\right)_{g r} ; \mathrm{q}_{j}^{\text {tec }} \leq\left(\mathrm{q}_{j}^{\text {tec }}\right)_{g r}
\end{array},\right.
$$

where $\left(\mathrm{q}_{i}^{k o n}\right)_{g r},\left(\mathrm{q}_{j}^{\text {tec }}\right)_{g r}$ are the boundary parameters values of design and technology.

As previously stated consumer characteristics $Q$ of a product $Y$ are shown in the design parameters $q^{k o n}$ and are realized if the technology parameters $q^{\text {tec }}$ are achieved, though the latter is not included in $Q$ in explicit form. In formalized form the connection between the parameters $\mathrm{Q}$ of a product and included parameters on the stages of design (construction) and production (technology) may be presented as follows (4) и (5):

$$
Q=\left[q_{i}^{k o n}\right] \cdot M
$$

where $M$ is the matrix of positive impact coefficients, $m_{i j} \geq 0$.

Not evident nature of connection between $\mathrm{Q}$ and $q^{\text {tec }}$ may be defined if we add the correlation matrix $\mathrm{K}$ between design and technological parameters according to (5):

$$
\left[\Delta q^{\text {tec }}\right]=K \cdot\left[\Delta q^{k o n}\right]^{T},
$$

where $\Delta q_{i}^{k o n}, \Delta q_{j}^{t e c}$ are the parameters value changes $q_{i}^{k o n}, q_{j}^{t e c}, k_{i j}$ is the correlation coefficient $-1 \leq k_{i j} \leq 1$.

At the moment there is no clear recommended practice to calculate the correlation matrix. To define its coefficients for instance expert evaluation method may be suggested. The given data for analysis and calculations $k_{i j}$ are the technical specifications contained in the design documentation of a product and parameters of standard techniques and procedures with reference to facilities of the specific production. 
It should be noted that between target functions DAE and TAE to achieve required level of parameters $q_{i}^{\text {tec }}, q_{j}^{k o n}$ there is often a contradiction, for instance, the requirement of weight reduction of a product, given in its design i.e. the increase of $q_{i}^{k o n}$ reduces its technological effectiveness i.e. reduces the value of $q_{j}^{\text {tec }}$. Consequently, if $k_{i j}<0$, in order to make the system self-regulating i.e. to make it reach the equilibrium state according to the Nash [10], it is necessary to add the coordination process between designers and technologists, as there are some contradictions between target functions of development $q_{i}^{k o n} \rightarrow \max$ и $q_{j}^{\text {tec }} \rightarrow \max$.

Let suppose that there is $Y$ an object of production - a design of a product, then $\Omega(Y)$ is seen as external environment, where $Q\left(\left\{q_{m}^{k o n}, q_{n}^{t e c}\right\}\right)$ are the parameters of production object, $w\left(\left\{p_{i}^{k o n}, p_{j}^{\text {tec }}\right\}, \mathrm{Q}\right)$ - production object display in design and technological documentation, where $p_{i}^{k o n}, p_{j}^{\text {tec }}$ are the action by designers and technologists, which lead to the results $q_{m}^{k o n}, q_{n}^{\text {tec }}$. If $\left\{p_{i}^{k o n}, p_{j}^{\text {tec }}\right\} \in P_{o p t}$ are the combined actions, then Nash equilibrium is true in the following way:

$$
\begin{aligned}
& E_{N}(\theta)=\left\{\left\{p_{i}^{k o n}, p_{j}^{\text {tec }}\right\}_{i \in I, j \in J} \in P_{i, j} \mid \forall i \in I, \forall j \in J, \forall\left\{\mathrm{y}_{i}^{k o n}, \mathrm{y}_{j}^{\text {tec }}\right\} \in P_{i, j}\right. \\
& f_{i}\left(\theta_{i},\left\{p_{i}^{\text {kon }}, p_{j}^{\text {tec }}\right\}_{1}, \ldots,\left\{p_{i}^{\text {kon }}, p_{j}^{\text {tec }}\right\}_{n}\right) \geq f_{i}\left(\theta_{i},\left(\left\{p_{i}^{k o n}, p_{j}^{\text {tec }}\right\}_{1}, \ldots,\left\{p_{i}^{k o n}, p_{j}^{\text {tec }}\right\}_{i-1},\left\{\mathrm{y}_{i}^{k o n}, \mathrm{y}_{j}^{\text {tec }}\right\}_{i},\right.\right. \\
& \left.\left.\left\{p_{i}^{\text {kon }}, p_{j}^{\text {tec }}\right\}_{i+1}, \ldots,\left\{p_{i}^{\text {kon }}, p_{j}^{\text {tec }}\right\}_{n}\right)\right\}, \theta \in \Omega^{n}(Y) .
\end{aligned}
$$

Thus, for the formalized DEPP system provided that the systems works within the time interval when it gradually gets through the states of $t_{1}, \ldots, t_{n}$, the necessary requirement for coordination of the interaction between DAE and TAE (3) is the achievement of Nash equilibrium.

In order to reach the Nash equilibrium according to the reflexive game theory [11] players (in our case they are designers and technologists) must have an adequate concept of the other team's actions. The availability of information resource of PDM/PLM for control system of a product LC Y is the requirement for accomplishment of (6) and, thus of (3).

Let us define the sufficient condition for accomplishment (3), i.e. let us carry out the justification of conditions and mechanisms of system self-regulation. Besides the performance of plan targets from the center $K_{x i}, T_{x j}$ the players (DAE and TAE) begin to cooperate with each other, for this purpose they fulfill some actions $U^{K T}\left(\mathrm{q}_{i}^{\mathrm{kon}}, \mathrm{q}_{j}^{\text {tec }}, \mathrm{t}\right)$ и $U^{T K}\left(\mathrm{q}_{i}^{\mathrm{kon}}, \mathrm{q}_{j}^{\text {tec }}, \mathrm{t}\right)$ shown in figure 1 . As an example of such actions from DEPP common practice we may refer to the stage of technologic coordination of design documentation at the machine-building enterprises. It is evident that to reach equilibrium at (6) the actions $U^{K T}\left(\mathrm{q}_{i}^{\text {kon }}, \mathrm{q}_{j}^{\text {tec }}, \mathrm{t}\right)$ and $U^{T K}\left(\mathrm{q}_{i}^{\text {kon }}, \mathrm{q}_{j}^{\text {tec }}, \mathrm{t}\right)$ must be task-oriented. The task orientation within the given context is understood as such actions of players $p_{i}^{k o n}=p_{i}^{k o n}\left(U^{K}, \mathrm{U}^{K T}\right), p_{j}^{t e c}=p_{j}^{t e c}\left(U^{T}, \mathrm{U}^{T K}\right)$ at (6), so that $K_{x i}, T_{x j}$ will be performed in a balanced manner. In other words DAE and TAE must be interested in outcomes of the opposite team's actions.

The task orientation $U^{K T}\left(\mathrm{q}_{i}^{\text {kon }}, \mathrm{q}_{j}^{\text {tec }}, \mathrm{t}\right)$ and $U^{T K}\left(\mathrm{q}_{i}^{\mathrm{kon}}, \mathrm{q}_{j}^{\text {tec }}, \mathrm{t}\right)$ may be achieved by means of introduction the mechanism of mutual interest from players in DAE and TAE in achieving the goal from the center, for instance, with the help of incentive mechanism with project time limit $t_{\Sigma}$. In this case the incentive mechanism serves as sufficient condition for accomplishing (3). For illustrative purposes let us consider the simplified scheme of such mechanism implementation based on incentive payment systems [12]. 


\section{Incentive mechanism in coordinated interaction with time limit $t \leq t_{\Sigma}$.}

The common form of the incentive model of production active elements in DEPP can be given as follows:

$$
\left\{\begin{array}{l}
V_{n}=f\left(K_{u z n}\left(D_{n}\right)\right) \rightarrow \max \\
\sum_{j=1}^{m 1} \sum_{k=1}^{m 2} \delta_{j k} \Delta t_{k} \leq t_{\Sigma} \\
\mathrm{q}_{i}^{\text {kon }} \leq\left(\mathrm{q}_{i}^{\text {kon }}\right)_{g r} ; \mathrm{q}_{j}^{\text {tec }} \leq\left(\mathrm{q}_{j}^{\text {tec }}\right)_{g r}
\end{array},\right.
$$

where $V_{n}$ is the value of incentive resource, $K_{\text {изм }}$ is the number of document change, $D_{n}$ is the working paper, $\mathrm{n}$ is the number of documents, $\mathrm{ml}$ is the number of employees in design and technological departments, $\mathrm{m} 2$ is the number of documents with LC elements, $t_{\Sigma}$ is the rate time at DEPP, $\delta_{\mathrm{jk}}$ is the competency matrix element of an employee, $\Delta \mathrm{t}_{\mathrm{k}}$ is the development efforts change of a document thanks to the coordinated decisions based on $U^{K T}\left(\mathrm{q}_{i}^{\mathrm{kon}}, \mathrm{q}_{i}^{\text {tec }}, \mathrm{t}\right)$ and $U^{T K}\left(\mathrm{q}_{i}^{\text {kon }}, \mathrm{q}_{j}^{\text {tec }}, \mathrm{t}\right)$.

In accordance with document oriented approach to DEPP it is necessary to minimize the number of document changes (design and technological) by means of using the incentive resources $V_{n}$, optimizing organizational resource $\left(U^{K T}\left(\mathrm{q}_{i}^{\mathrm{kon}}, \mathrm{q}_{j}^{\text {tec }}, \mathrm{t}\right)\right.$ and $\left.U^{T K}\left(\mathrm{q}_{i}^{\mathrm{kon}}, \mathrm{q}_{j}^{\text {tec }}, \mathrm{t}\right)\right)$. As a result an employee of a department may work out more documents $\left(\mathrm{D}_{\mathrm{n}}\right)$, due to the optimization of a document LC (reduction of number and cutting time). Simply stated, every project document goes through the following stages of LC: D (DI, S, C, $S_{2}$ ), where DI is the development with labour intensity $\left(t_{\text {dev }}\right), S$ is the statement $\left(t_{\text {stat }}\right), C$ is the change $\left(t_{c h}\right), S_{2}$ is the statement $\left(t_{s t a t}\right)$. During the optimization process due to the change reduction the competency matrix suffers the redistribution (table 1).

Table 1. Competency matrix of organizational system with parameter $\delta_{\mathrm{jk}}: \delta_{\mathrm{jk}}=1$, if an employee works with a document; 0 - the other way.

\begin{tabular}{|c|c|c|c|c|c|c|c|c|}
\hline Employees & \multicolumn{8}{|c|}{ Documents (on project stages) } \\
\hline & $\mathrm{D}_{\mathrm{p}}{ }^{1}$ & $\mathrm{D}_{\mathrm{y}}{ }^{1}$ & $\mathrm{D}_{\text {и }}{ }^{1}$ & $\mathrm{D}_{\mathrm{y} 2}{ }^{1}$ & $\mathrm{D}_{\mathrm{p}}{ }^{2}$ & $\mathrm{D}_{\mathrm{y}}{ }^{2}$ & $\mathrm{D}_{\mathrm{u}}{ }^{2}$ & $\mathrm{D}_{\mathrm{y} 2}{ }^{2}$ \\
\hline 1 & 1 & 0 & 1 & 0 & 1 & 0 & 1 & 0 \\
\hline$\ldots$ & & & & & & & & \\
\hline $\mathrm{k}$ & 0 & 1 & 0 & 1 & 0 & 1 & 0 & 1 \\
\hline
\end{tabular}

The work with documents is combined for a specific employee if the amount of work is less than counterpart, i.e. $\Lambda=\left\{\mathrm{O}_{\mathrm{j}} \leq \mathrm{K}_{\mathrm{i}} \mathrm{t}_{\mathrm{j}} \mathrm{Z}_{\mathrm{i}}\right\}=1$, then the work $\mathrm{j}$ is fulfilled by I employee; if it is 0 , then we add some work to the employee, where $\mathrm{K}$ is the number of employees working on the project, $\mathrm{Z}$ is the employment of workers, $t$ is the labour intensity of document development.

The incentive system may be the motivation of change quantity reduction in design and technological departments: $100 \%$ of change reduction leads to benefit increase at $10 \%$, i.e. the following dependence is formed: $\mathrm{V}=\mathrm{f}\left(\mathrm{K}_{\mathrm{ch}}\right)$, where $\mathrm{V}$ is the amount of benefit, $\mathrm{K}_{\mathrm{ch}}$ is the number of document changes (figure 2).

The dependence of incentive resource value from reduction of change number can be illustrated by the following example. There are two employees from different departments with competences stated in Table 1. With coordinated interaction according to (3) the first employee reduced the time spent on design document development at 10 days, while the second employee reduced it on technological document development at 20 days, the whole project took 150 days $\left(t_{\Sigma}\right)$.

It is as follows: $\sum_{j=1}^{m 1} \sum_{k=1}^{m 2} \delta_{j k} \Delta t_{k}=1 \cdot 10+1+1+1+1 \cdot 20+1+1+1 \leq t_{\Sigma}=150$.

The amount of benefit for coordinated interaction may be defined from target function (7) and the graph from the figure 2. As time on development was reduced at 30 days (or $20 \%$ from 150 days of total days for project), then according to the graph the amount of benefit payment must be $20 \%$ from basic amount $V$. 


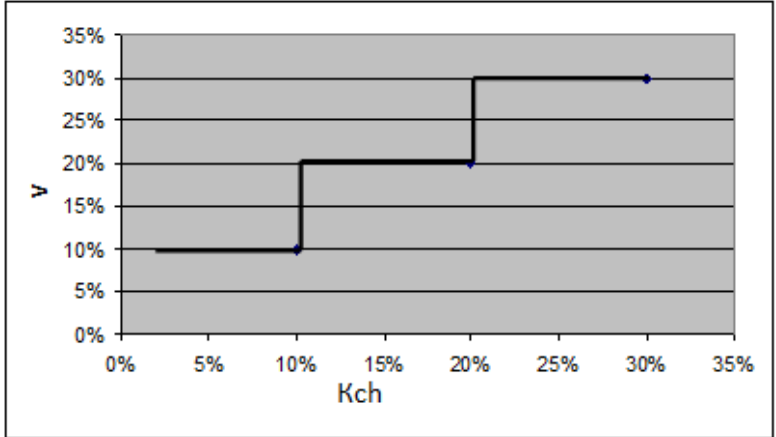

Figure 2. The dependence of benefit amount $(\mathrm{V})$ from reduction of numbers of document changes $\left(\mathrm{K}_{\mathrm{ch}}\right)$.

\section{Implementation of the incentive mechanism in the design and technological preparation of production using the information processing level}

The incentive mechanism developed above with the coordination of interests in the DEPP can be realized in the context of a single information space of the enterprise. For implementation, it is necessary to develop a structure for the information processing level through the integration of data models of product data management systems (PDM) and event management systems (PEM).

The data model in the PDM system should consist of product design data in the form of a tree with part and assembly units, attribute data and relationships between the elements in the form of project tree, the geometry data of the product in the form of 3D models. Also, the data model should contain a set of design and technological documentation and data on notifications of changes and preliminary notice of a change after working out the "Coordination" unit with the incentive mechanism.

The model of classes in the PEM system can be deployed using Big Data technology to store information about changes in configuration of structures and technologies for all parts and assembly units of the product, data on the events of version changes and task execution, as well as creating cloud services for processing and analysis data.

Big Data technology consists of two components: a connected cluster system and a programming interface. Basically the work of these technologies is connected with three basic principles. Firstly, the data is evenly distributed on the internal disks of many servers, and in the systems of design and technological preparation for production data on the design and technology are on different servers, and when working with an aviation cluster they are on different continents. Secondly, it is not the data which is transferred to the processing program, but the program is transferred to the data. The third principle is that data is processed in parallel, and this possibility is embedded architecturally in the program interface. Thus, instead of the usual "database-server" concept, there is a cluster of many inexpensive nodes, each of which is both a repository and a data processor, and the concept of a "database" is absent. This system has two important characteristics: any complex analysis of a large amount of data is reduced to processing them on the local disks of the server, i.e. the maximum possible reaction time is known in advance; the system is scaled symmetrically and linearly, i.e. the processing time does not depend on their volume [13].

At production enterprises under the concept of CALS, these classes of systems will constitute a single information space of the enterprise and store all information related to information support for all stages of the product life cycle, that is, they will become the only reliable source of up-to-date data.

The accumulated information in the field of design and technological preparation of production at the enterprise is an important asset, but the time spent searching for huge amounts of data does not justify the production process. In aviation and automotive enterprises, the need to introduce large data processing technologies was previously lacking, as the data for designers and technologists were structured, and a relational data model and a database management system existed to work with the structured data flow, but with a huge flow of unstructured data associated with data on operation of equipment in technological processes, in notifications of changes after the detection of defects in prototypes of products obtained from the power of audio and streaming data from a variety of 
counters, etc., the old approaches have stopped working. The relevance of this problem has led to the ever growing interest in Big Data class technologies and the emergence of new modules in PDM systems (for example, TEAMCENTER: Big Data).

These modules will allow us to modernize the single information space of the enterprise, taking into account the provision of the required quality level, both the products manufactured and the production processes in general, in the conditions of constant product improvement through notifications of changes, shortening the terms of design and technological preparation of production and through the use of modern methods of operational planning, based on the current information using data protection tools in the form of tables with a access rights differentiation to information.

The purpose of integration of information resources of the enterprise is to ensure effective interaction between designers and technologists, as well as the accumulation of structured and unstructured data, their distribution and quality processing, and the subsequent compilation of statistics based on them.

The general structure of the new class model in the PDM system and in the PEM system is shown in figure 3.

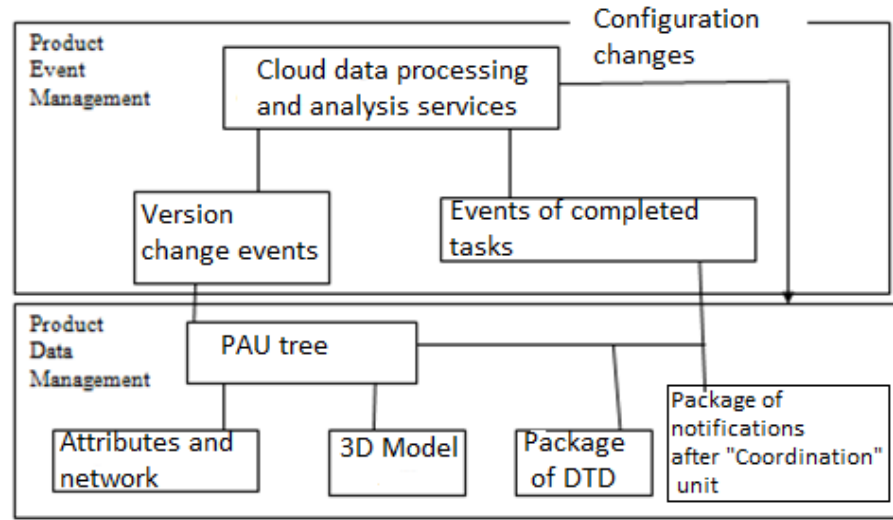

Figure 3. Data presentation level in single information space.

\section{Results and discussion}

The process of DEPP may be described as a hierarchical active system "center -designers technologists" in DEPP; however a functioning model of the production of the active element in the system is a model of decision making. Task oriented decision, chosen by each active member as a team, lead to the definite state of the system and may be different from the planned states that are defined by the center. The latter may lead to contradictions in the system in making practical engineering decisions in modeling of materials $[14,15,16]$. Because of that the quantitative assessment of inconsistency in decision making between teams was introduced, and the coordinated interaction task was stated. Based on the Nash equilibrium it was stated that it is possible to achieve balanced solving of contradiction problem between active elements of the system the designers (DAE) and the technologists (TAE). Due to this fact it is justified that mutual consideration of goals of active elements apart from the goals of the center is the required condition when controlling DEPP in mode of self-regulation.

The achievement of coordinated balance (on actions and goals of subsystems) may be reached with the help of incentive mechanism introduction for active elements. The task of coordinated cooperation in DEPP may be solved by choosing the additional effect function for active elements, connected with benefit payments for reduction changes in documents, which is a variable of their target functions.

\section{References}

[1] Agafonov A A and Myasnikov V V 2016 Computer Optics 40(2) 275-283

[2] Vasin Yu G and Yasakov Yu V 2016 Computer Optics 40(6) 919-928

[3] Grechnikov F V and Khaimovich A I 2015 CEUR Workshop Proceedings 1490 364-375 
[4] Grechnikov F V, Dem'yanenko E G and Popov I P 2015 Russian Journal of Non-Ferrous Metals 56(1) 15-19.

[5] Geraskin M I 2017 CEUR Workshop Proceedings 1903 92-99

[6] Haimovich I N and Frolov M A 2016 Key engineering materials 684 487-507

[7] Morozov V V, Kirichenko A S and Khaimovich I N 2013 Kuznechno-shtampovochnoe proizvodstvo Obrabotka materialov davleniem $342-48$ (in Russian)

[8] Balashov V G 2002 Autom. Remote Control. 12 92-95

[9] Burkov V N and Burkova I V 2014 Autom. Remote Control. 3 73-86

[10] Burkova I V 2009 Autom. Remote Control. 10 15-21

[11] Novikov D A 2012 Autom. Remote Control. $13-23$

[12] Novikov D A 2008 Publishing House of Physical and Mathematical Literature 139

[13] Leontiev S V, Novikov D A and Petrakov S N 2002 Autom. Remote Control. 7 107-116

[14] Zalozhnev D A, Kalashnikov A O and Novikov D A 2007 Autom. Remote Control. 3 142-153

[15] Ivashchenko A V, Dvoinina O V and Lednev A M 201Entellect. Innovations. Investments. 2 58-64

[16] Kirichenko A S and Khaimovich I N 2011 Bulletin of the Samara State University 2 276-281 (in Russian) 